\title{
Contra el espacio público: criminalización e higienización en la migración peruana en Santiago de Chile
}

Alejandro Garcés. Universidad Católica del Norte, Antofagasta, Chile.

RESUMEN | A partir de una exploración etnográfica de los usos y apropiaciones del espacio urbano de la ciudad de Santiago de Chile, y de la utilización de fuentes secundarias -como estadísticas y producciones cartográficas-, el presente artículo describe y explica la actuación de los dispositivos de criminalización e higienización de los espacios ocupados por los grupos migrantes peruanos en el marco de su inserción urbana y su reproducción económica y social como colectivo en la ciudad, en este caso escenificadas por la práctica del comercio ambulante. De la comparación entre dos espacios concretos de la ciudad emerge la contemporánea patrimonialización de los espacios urbanos y la reificación de la clausura espacial del colectivo, como vectores que cruzan tanto a migrantes como a autóctonos en la producción del espacio en tanto contenedor de una cultura y relaciones sociales específicas.

PALABras Clave | economía informal, conflicto social, espacio público.

ABSTRACT | On the basis of an ethnographic exploration of the uses and appropriation of urban space in the city of Santiago de Chile, complemented by secondary resources such as demographic statistics and maps, this article describes and explains the devices of criminalization and sanitization of the urban spaces occupied by Peruvian migrants in the context of their insertion and reproduction as a social collective in the city. This process will be exemplified by the Peruvian practice of street vending. The comparison between two specific urban scenarios guides the analysis through the contemporary process of the patrimonialization of urban spaces, and reification of the spatial enclosure of the Peru-vian collective. Both of these aspects represent vectors that include both migrants and native residents, who together establish the conditions for the production of space, particularly in its capacity as a container of a specific culture and specific social relations.

KEY WORDs | informal economy, social conflict, public space.

Recibido el 20 de agosto de 2012, aprobado el 23 de abril de 2013

Email: ajgarces@gmail.com, agarces@ucn.cl 


\section{Introducción}

En el contexto de la ocupación de espacios urbanos por parte de la migración peruana en Santiago de Chile -su polifuncionalidad y polisemia producida a partir de distintas prácticas y discursos-, analizaremos en el presente artículo algunas expresiones de la tensión resultante de la apropiación del espacio público operada por los y las peruanas en dicha ciudad. Indagamos centralmente en tres aspectos del fenómeno: (i) los modos en que son comprendidas o significadas las diferencias que la localización de lo migrante introduce en el conjunto urbano en cuanto producción de heterogeneidad; (ii) los modos en que, desde lo nativo-chileno, pueden ser tematizadas estas nuevas localizaciones; y (iii) la operación mediante la cual estos discursos son apropiados por los mismos migrantes a los efectos de (re)producir diferencias al interior del espacio. Consecuentemente, el texto se organiza por medio de una entrada que prefigura el proceso de apropiación del espacio público operado por los migrantes peruanos (en particular el comercio ambulante de comidas); un segundo apartado que describe la actuación de un dispositivo de criminalización de los espacios ocupados por migrantes; y un tercero que ilustra la operación del dispositivo de higienización del espacio. Metodológicamente, trabajamos a partir del análisis de fuentes secundarias, como informes estadísticos y actas de concejos municipales de la comuna de Santiago, al mismo tiempo que desarrollamos un proceso etnográfico en distintas fases entre el 2006 y 2009 (en los espacios de concentración residencial/comercial de calle Catedral en la comuna de Santiago, y de calle Rivera en la comuna de Independencia).

En otros trabajos hemos caracterizado las formas de apropiación de algunos espacios urbanos por parte del colectivo, su relevancia para la reproducción económica y social del mismo, y su desbordamiento para constituirse en nodo de una movilidad urbana y soporte de una dinámica transnacional (Garcés, 2011b; 2012). A continuación veremos cómo algunas fuerzas operan en el sentido contrario de ese desborde, apuntando a un reforzamiento de sus fronteras mediante una localización de lo peruano que se configura mediante su segregación y estigmatización.

La intensa actividad del comercio ambulante en algunos espacios centrales de la ciudad -las mencionadas calles Catedral y Rivera-, sumada a los grupos informales allí reunidos y la gran cantidad de locales comerciales orientados hacia los consumos migrantes, tiñen dichos lugares de nuevos sonidos, colores y olores que los distinguen sin duda de cualquier otra zona del centro, haciendo imposible que pasen inadvertidos para el común de los transeúntes locales. Si, por un lado, podemos observar las posibilidades del espacio como locus de recursos migrantes (al producir un lugar de encuentro, de acceso a empleo o a vivienda) (Schiapacasse, 2008; Ducci \& Rojas, 2010), a continuación nos concentramos en cómo, a partir de la visibilidad de la actividad comercial ambulante, el espacio se revela como objeto de disputa, de lucha por la hegemonía de sus usos legítimos. 


\section{Entrada: de disciplina y construcción espacial}

Siguiendo al geógrafo Mitchell (2003) en su análisis del fenómeno homeless en ciudades norteamericanas, vemos ilustrada la idea de una disputa por el espacio público. Este engendraría miedos al tratarse de un territorio incontrolado, o supuestamente incontrolado: un espacio en que la civilización sería excepcionalmente frágil. Resulta interesante la afirmación del autor respecto de que los usos del espacio público por parte de algunos homeless son vistos por ellos como estrategia de supervivencia, mientras que para sus detractores se trataría simplemente de una afrenta al orden, dignidad y civilización de la ciudad (ibíd., 2003, pp. 12-15).

En esta línea, Lefebvre $(1973 ; 1976)$ defiende una noción de ciudad entendida como lugar de interacción social e intercambio con gente necesariamente diferente; un locus con alta densidad humana, que atrae constantemente a nuevos inmigrantes, componiéndose como una "fábrica de heterogeneidad" que es siempre objeto de lucha, objeto en disputa. Estos locus ponen siempre en relación a individuos y grupos con proyectos y formas de apropiación diversa respecto del espacio. Así, en paralelo o como efecto de estas disputas, la ciudad aparece como trabajo u obra en la que emergen o son inventados nuevos modos de vivir, nuevos modos de habitar, nuevas formas de producir lo urbano (Mitchell, 2003, p. 18).

Consideramos que los usos del espacio por parte de los peruanos en Santiago escenifican una cierta y concreta sociabilidad migrante al interior de la ciudad (Garcés, 2011a; 2011b). Estos usos inhiben u obstaculizan las posibilidades de un espacio público organizado en torno al anonimato. Configuran una dinámica opuesta a la especificidad de las identidades individuales, centrándose en el espacio urbano como práctica del movimiento, la circulación, las trayectorias individuales; un escenario inestable, si se quiere volátil (Delgado, 1999, p. 12). Los lugares que localizan privilegiadamente la experiencia de la migración peruana en Santiago se ubican en zonas céntricas de la ciudad, zonas de intenso movimiento que podrían ser caracterizadas como lugares inestables, de pura circulación, escenarios ideales para la operación del principio definitorio de las relaciones sociales en público, aquel que caracterizaría Goffman (1979) como la desatención cortés (véase también Delgado, 2007; Torres Pérez, 2008). Sin embargo, el entorno construido ${ }^{1}$ por los migrantes peruanos parece operar precisamente en sentido contrario. El carácter recurrente de las distintas prácticas de construcción del espacio (Corsín-Jiménez, 2003)², al mismo tiempo que el conjunto de relaciones cara a cara, familiares y/o comunitarias que se articulan en su interior, apuntan precisamente a la derogación del anonimato. La sociabilidad que aquí se impone tiende a una alta estructuración de las relaciones y a la certificación de una membrecía que descansa firmemente en la identidad (para

1 Siguiendo a Lawrence-Zúniga y Low (1990, p. 454), podemos entender el entorno construido como el producto de la actividad de un grupo humano determinado; en términos amplios, trataría de la alteración física del ambiente natural, desde hogares a ciudades.

2 Esta "recurrencia" está ordenada según un régimen temporal donde la diferencia entre días laborales y fin de semana resulta fundamental al momento de distinguir entre tipos de actividad e intensidad en el uso los espacios. Pertinente en este sentido es la noción de geografías temporales que CorsínJiménez (2005) desarrolla en su etnografía del espacio urbano de la ciudad de Antofagasta. 
empezar, nacional) de sus participantes. Nos encontramos ante prácticas de ocupación del espacio urbano, ante conflictos surgidos desde la co-presencia de lo inmigrante y lo autóctono, y ante la enunciación de discursos que anclan lo peruano a un territorio urbano específico. Todos estos elementos inhiben la posibilidad de sancionar o fijar una urbanidad a priori o anterior, aséptica, regida por el anonimato.

Como síntoma del carácter conflictivo que adoptan los usos del espacio por la población peruana, podemos entender la importancia dada al fenómeno como tema de debate en la campaña para las elecciones municipales de octubre de 2008. En la comuna de Santiago, la elección enfrentó a un candidato de la derecha con uno de la coalición de centroizquierda, aquella que gobernó el país desde la llamada "vuelta a la democracia" (1990-2010). Un periódico de circulación nacional retrató así la discusión sobre los peruanos en el centro de Santiago: "Ravinet fue mucho más tajante, porque lo que se debe hacer, según el candidato, es 'arrendar una casa o galería donde [los migrantes peruanos] tengan una sede. El uso del espacio público en forma permanente es una falta municipal, propongo arrendar una galería donde tengan la Casa del Perú" (La Tercera, 22 de octubre de 2008).

Lo que se presenta es la primacía de una noción de espacio público que, además de despolitizado, sanciona como falta municipal la permanencia sin más en él, privilegiando una concepción del espacio centrada en la pura y aséptica circulación de personas y cosas. Se impone lo que podría entenderse como representaciones del espacio: espacios concebidos desde lógicas dominantes de los saberes técnicos, racionales, tecnócratas (Lefebvre, 1991). Lo que el candidato manifiesta es el solapamiento o la colusión del poder político con estos saberes que dominan el espacio público ${ }^{3}$.

Es justamente esta ocupación permanente del espacio público -constitutiva de una falta municipal o convertida en un objeto de ayuda, que no política- lo que vendría a constituir ya no representaciones del espacio, sino espacios de representación (Lefebvre, 1991). Estos serían los espacios vividos, mundos compuestos de conocimientos locales, pautas de significación y lógicas de interacción específicas entre individuos y grupos. La vińeta periodística es sintomática de la tensión entre estos dos tipos de espacios o saberes que se proyectan sobre lo urbano, ya que "el espacio no es simplemente el dominio del estado que lo administra, ordena y controla (representaciones del espacio), sino la siempre dinámica y fluida interacción entre lo local y lo global, lo individual y lo colectivo, lo privado y lo público, y entre resistencia y dominación" (Oslender, 2002, s/p).

Las apropiaciones en curso de la migración peruana en Santiago imponen una cierta heterogeneidad al espacio urbano, legitimando presencias y prácticas específicas. Producen un disciplinamiento del espacio, porque articulan un principio de clausura, esto es, la especificación de un lugar heterogéneo a los demás y cerrado sobre sí mismo, un lugar protegido o inscrito en la monotonía disciplinaria. La

3 Se trata de saberes que "están vinculados con las instituciones del poder dominante y con las representaciones normalizadas generadas por una lógica de visualización hegemónica. Están representados como espacios legibles, por ejemplo en mapas, estadísticas, etcétera. Producen visiones y representaciones normalizadas en las estructuras estatales, en la economía y en la sociedad civil. Esta legibilidad produce efectivamente una simplificación del espacio, como si se tratara de una superficie transparente" (Oslender, 2002, s/n). 
disciplina emerge como arte de la distribución de individuos en el espacio, realizada por la técnica de otorgar a cada individuo un lugar y a cada emplazamiento un individuo (Foucault, 2002, pp. 145-146).

Este disciplinamiento por medio de los usos y permanencias de la experiencia migrante entra en contradicción con otro tipo de disciplinamiento espacial: el de la planificación urbana. Esta última pretende reafirmar usos legítimos del espacio, definiéndolos como supuestamente anteriores a la producción cotidiana de lo urbano. En gran medida, esta planificación niega la producción diaria de lo urbano, ya que esta última nace de la calle o de aquello que en ella se ejecuta o despliega (Delgado, 2007, p. 14). La presencia de peruanos y su apropiación del espacio público santiaguino desafía la planificación urbana, desplegando precisamente otra urbanidad, esta vez anómala: la anomalía de lo migrante. Se trata de una aglomeración de personas que destruye las líneas de circulación por el espacio, o más bien las lógicas de esa circulación supuestamente consustanciales al espacio público. Frente a la disciplina -constituida para conocer, dominar y utilizar-, los usos migrantes del espacio la hacen opaca, borran su visibilidad, la hacen ilegible, configurando un espacio indisciplinado.

Si tenemos esta discontinuidad, esta producción de heterogeneidad introducida por la presencia migrante, debemos preguntarnos entonces por la manera en que dicha presencia es tematizada; por qué mecanismos es denotado su indisciplinamiento, y cuál es el orden que este indisciplinamiento subvierte. A continuación distinguimos diversos actores que, desde la institucionalidad pública local, desde los propios consumidores migrantes, comerciantes y representantes de organizaciones, además de algunos pequeños empresarios chilenos, van cooperando en la construcción de esta escena, contribuyendo simultáneamente a la delimitación de unos espacios para lo peruano en Santiago.

\section{Ilegalidad e inseguridad en un espacio criminalizado}

Una de las cuestiones más notorias respecto de cómo son percibidos los espacios urbanos de concentración residencial y comercial del colectivo peruano en Santiago es su asociación con la idea de inseguridad, debido a la ocurrencia ya sea de actividades delictivas de distinto tipo en su interior, o bien de meras reyertas entre los migrantes o entre estos y la población local.

Con independencia de si se trata de una inseguridad "real" (fundamentada en una mayor frecuencia de delitos), o de una "percepción" (fundada en prejuicios o estereotipos que acompańan la producción de los medios de comunicación de masas), lo que en la práctica se genera es un nuevo esfuerzo delimitador de espacios dentro de la ciudad, que en este caso vincula la migración con el desarrollo de prácticas ilegales que lesionan aquello que, desde la vuelta a la democracia en Chile (ańos noventa), se denomina el problema de la "seguridad ciudadana". Estas vinculaciones redundan en una criminalización de los espacios urbanos de la migración peruana, proceso que no opera unívocamente desde las agencias de la sociedad chilena hacia la población migrante, sino que -como veremos- se introyecta o reproduce al interior de los colectivos migrantes. 
El monitoreo de medios que realiza en este orden el Observatorio Experimental sobre las Migraciones en las Áreas Urbanas de América Latina (Miurbal) es importante y sintomático de lo que planteamos. A partir del análisis de las noticias en cuatro medios de prensa escrita de circulación nacional en Chile (Arriagada \& Granifo, 2008) se establece la siguiente tabla de frecuencias de aparición noticiosa de la migración internacional en Santiago (Cuadro 1).

CUADRo 1 | Ranking de frecuencia de artículos publicados por tema.

Período sept.-dic. 2007

\begin{tabular}{|l|c|c|}
\hline \multicolumn{1}{|c|}{ TóPICO } & $\mathbf{N}^{\mathbf{0}}$ & \% \\
\hline Crímenes cometidos por inmigrantes & 19 & 35,85 \\
\hline Integración & 16 & 30,19 \\
\hline Otro & 7 & 13,21 \\
\hline Crimen contra inmigrante & 5 & 9,43 \\
\hline Política y control migratorio & 3 & 5,66 \\
\hline Arte y cultura & 2 & 3,77 \\
\hline Condiciones de vida & 1 & 1,89 \\
\hline Total & 53 & 100,00 \\
\hline
\end{tabular}

FUENTE ELABORACIÓN PROPIA A PARTIR DE DATOS DEL OBSERVATORIO DE MIGRACIÓN INTERNACIONAL EN SANTIAgo DE CHILE, DEL DEPARTAMENTO DE SOCIOlogía, UNiVERSIDAD DE CHILE

Se observa cómo bajo el tópico "crímenes cometidos por inmigrantes" queda expresada la mayor frecuencia con que la migración aparece vinculada a lo delictual. Se presenta una cierta estabilidad de esta representación: el tópico alcanza el 38,77\% en el ranking de frecuencias elaborado por el Observatorio para el período entre enero y mayo de 2007. Estos datos no distinguen de manera específica la concentración residencial y comercial que nos ocupa, pero prefiguran un elemento del contexto en el que esta concentración se da. Por lo demás, delitos o infracciones supuestamente cometidos por migrantes peruanos constituyen un descriptor central en discursos de migrantes y nativos respecto de espacios de concentración residencial/comercial de la migración. La imagen del colectivo peruano se está jugando también en los medios, donde la vinculación entre migrantes, espacios y prácticas comienza a hacerse más evidente:

Ha empeorado porque ahora la gente se reúne y es malo porque empiezan a conversar, comen, botan la basura, es algo que da mala imagen. Y eso se pasa a la prensa, al punto de que cuando hacen un reportaje lo primero que muestran es Catedral; no hay nadie aquí que no sepa dónde están los peruanos (H., peruano, comerciante de telefonía e Internet).

Por otro lado, donde sí aparece más directamente la dimensión espacial -o la referencia a las áreas de concentración residencial/comercial de la migración peruanaes en los informes de análisis relativos a la seguridad y delincuencia en la ciudad elaborados por organismos públicos. Los datos así producidos son de singular 
importancia, debido a que posteriormente fundamentan u organizan determinadas estrategias y políticas públicas de seguridad, en que el componente represivo emerge con notoriedad en los espacios ocupados por migrantes peruanos.

Las estadísticas de denuncias y detenciones por delitos de mayor connotación social (DMCs) - robos con violencia o intimidación, robos por sorpresa, robos con fuerza, hurtos, lesiones, homicidios, violaciones-, elaboradas trimestralmente por la División de Seguridad Pública del Ministerio del Interior de Chile, permiten observar dos fenómenos de singular significación. En primer lugar, el importante aumento de denuncias y detenciones en el intervalo que va desde el primer trimestre de 2006 al segundo de 2007. El Cuadro 2 expresa esta tendencia, distinguiendo los dos espacios de concentración estudiados: calle Catedral (comuna de Santiago Centro), y calle Rivera (comuna de Independencia).

CUADRo 2 Frecuencia de DMCs por tipo de parte y sector

\begin{tabular}{|c|c|c|c|c|c|c|c|c|}
\hline $\begin{array}{c}\text { TIPO } \\
\text { DE } \\
\text { PARTE }\end{array}$ & SECTOR & DELITO & $\begin{array}{c}\mathbf{I}^{\mathrm{ER}} \\
\text { TRIMESTRE } \\
\mathbf{2 0 0 6}\end{array}$ & $\begin{array}{c}\mathbf{2}^{\mathrm{DO}} \\
\text { TRIMESTRE } \\
\mathbf{2 0 0 6}\end{array}$ & $\begin{array}{c}\mathbf{3}^{\mathrm{ER}} \\
\text { TRIMESTRE } \\
\mathbf{2 0 0 6}\end{array}$ & $\begin{array}{c}\mathbf{4}^{\mathrm{TO}} \\
\text { TRIMESTRE } \\
\mathbf{2 0 0 6}\end{array}$ & $\begin{array}{c}\mathbf{I}^{\mathrm{ER}} \\
\text { TRIMESTRE }^{2007}\end{array}$ & $\begin{array}{c}\mathbf{2}^{\mathrm{DO}} \\
\text { TRIMESTRE }^{\mathbf{2 0 0 7}}\end{array}$ \\
\hline Denuncia & Catedral & DMCS & 174 & 220 & 240 & 234 & 241 & 282 \\
\hline Detención & Catedral & DMCS & 200 & 232 & 216 & 242 & 228 & 248 \\
\hline Denuncia & Rivera & DMCS & 96 & 136 & 140 & 124 & 107 & 139 \\
\hline Detención & Rivera & DMCS & 11 & 27 & 12 & 22 & 25 & 25 \\
\hline
\end{tabular}

FUENTE ELABORACIÓN PROPIA A PARTIR DE DATOS DE LA DIVISIÓN DE SEGURIDAD PÚBLICA, MINISTERIO DEL INTERIOR, GOBIERNO DE CHILE

Si bien existen algunos períodos, los menos, en que hay una baja en las frecuencias de denuncia y detención, si comparamos los valores iniciales del primer semestre de 2006 con los del segundo de 2007, para ambos sectores, notamos un importante aumento de la frecuencia de delitos, lo que podemos interpretar como la consolidación de estos sectores como espacios "conflictivos" en la ciudad.

En segundo lugar, y más importante en la perspectiva de la dimensión espacial: estas estadísticas respaldan la elaboración de planos que permiten localizar zonas específicas de la ciudad en que la ocurrencia de estos hechos es más frecuente, denominadas "áreas de concentración delictual" por la División de Seguridad Pública del Ministerio del Interior. Lo interesante para nuestro análisis es que las áreas de concentración delictual tienden a coincidir con los espacios de concentración de la migración peruana en general y, específicamente, con la ubicación de sus comercios: con el conjunto de espacios públicos que constituyen el escenario de sociabilidad de la migración peruana en Santiago.

Los siguientes planos representan los espacios estudiados en cuanto "áreas de concentración delictual" según delitos de mayor connotación social. En ellos vemos cómo las denuncias y detenciones intensifican su frecuencia en las cercanías de zonas donde se ubican comercios peruanos de telefonía, Internet y ocio (discotecas, restaurantes). Así, la criminalización del espacio es producto de la actuación de un dispositivo de poder desde lo institucional-público chileno, que se expresa 
materialmente por la construcción de estadísticas y/o cartografías del delito protagonizadas por la presencia de migrantes (Figuras 1 y 2).

FIgURA 1 | Áreas de concentración delictual por DMCs, calle Catedral

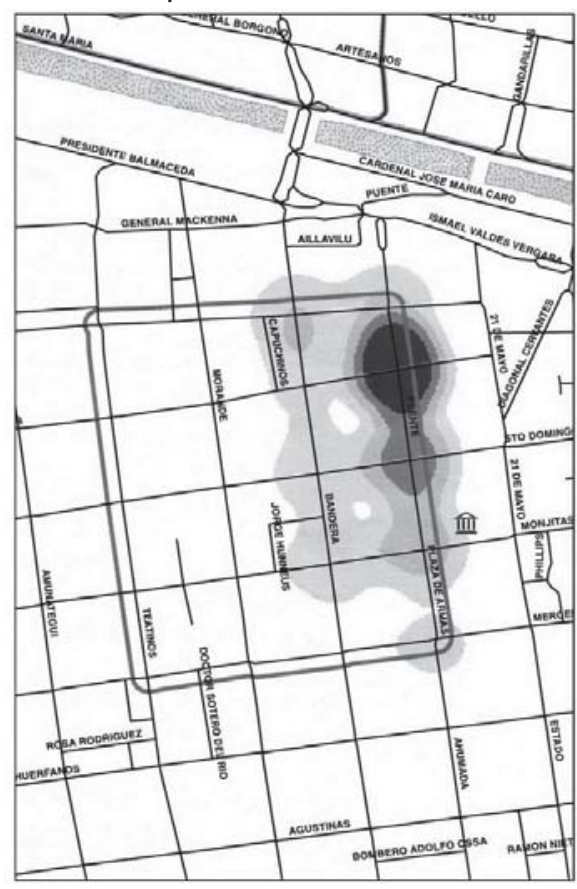

FUENTE DIVISIÓN DE SEGURIDAD PÚBLICA, MINISTERIO DEL INTERIOR, GOBIERNO DE CHILE

FIGURA 2 | Áreas de concentración delictual por DMCs, calle Rivera

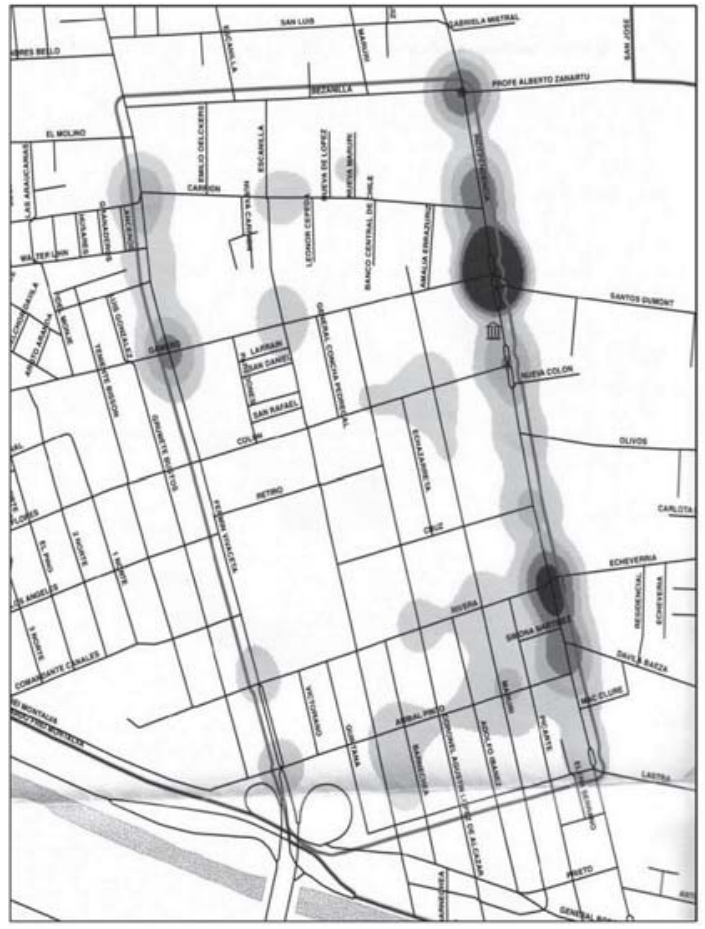

FUENTE DIVISIÓN DE SEGURIDAD PÚBLICA, MINISTERIO DEL INTERIOR, GOBIERNO DE CHILE 
Se presenta una delimitación de espacios urbanos ocupados por la migración peruana, y una cierta vinculación con lo delictual e inseguro en la ciudad. La producción de esta cartografía como dispositivo inaugura un escenario de diversas actuaciones que, desde el aparato estatal, establecen una presión sobre los espacios y sobre quienes participan de ellos. Se configuran así mecanismos que cooperan en la fijación/demarcación de un territorio específico en la ciudad, denotando o construyendo, simultáneamente, significados sobre el espacio y sus ocupantes.

En esta clave pueden interpretarse la continua presencia policial en las calles y la realización de redadas para detención de personas indocumentadas. Es sintomática también la presencia, desde hace tres años, de un bus policial en calle Catedral durante todo el día, todos los días del año, formando parte del paisaje urbano del barrio o, más bien, marcándolo o estigmatizándolo, según lo que hemos planteado. Desde la perspectiva de algunos pequeños empresarios del sector, la acción de Carabineros ${ }^{4}$ resulta desproporcionada y discriminadora.

La única inseguridad que tenemos es la de los mismos carabineros... Nos han hecho allanamiento sin que tuvieran denuncia ni nada, han entrado a detener gente dentro del local. A uno de los empleados lo detuvieron, y cuando preguntó por qué, le dijeron que lo detenían por feo, aunque en realidad era feo [risas]. Luego le dijeron que era porque estaba robando. Puro racismo, mal trato, porque él es uno de mis empleados de confianza... no había ni denuncia ni nada. La inseguridad nuestra pasa por lo de los carabineros (L., empresario chileno del rubro Telefonía e Internet).

Simultáneamente, emergen desde esta delimitación otras actuaciones, ya no necesariamente policiales, sino que de orden administrativo, relacionadas con el conjunto de procedimientos que demandan la instalación y mantención de negocios por los nuevos emprendedores migrantes. El "hostigamiento" de los funcionarios municipales, sanitarios y de Impuestos Internos, del que suelen sentirse víctimas los comerciantes peruanos, ilustra esta presión que verificamos sobre el espacio:

En el último tiempo vienen bastante los de Impuestos Internos, vienen bastante a este barrio. Impuestos Internos, el SESMA 5 , la Municipalidad, o sea, en realidad todas las entidades públicas... Los de la Municipalidad vienen a chequear porque, según lo que dicen ellos, hay denuncias, hay reclamos... Y yo me siento mal con eso, de una manera me siento presionado, porque constantemente andan mirando. Yo tengo hasta multas, yo tengo que ir a solucionarlas; me tomo mi tiempo para eso, pero es molestoso para mí, porque en realidad lo único que yo hago acá es trabajar. Nos hacen más complicado para nosotros sacar los papeles, los permisos, la patente... En relación a los chilenos, nos fastidian bastante. En este barrio yo creo que es donde más tiempo se toma el de Impuestos Internos, del sesma, de la Municipalidad, andan constantemente... Uno se da cuenta, la forma como ellos vienen, hay veces que vienen cada dos días. Anteayer me visitó un funcionario, hoy viene

$4 \quad$ Fuerza policial encargada del orden público en Chile.

5 Antiguo Servicio de Salud Metropolitano del Ambiente, cuyas funciones de control sanitario realiza actualmente la Autoridad Sanitaria Metropolitana. La mayor parte de comerciantes hace caso omiso a esta transformación y se refiere a esta institución como 'el SESMA'. 
otro funcionario... Antes, por ejemplo, hace un año, cuando todavía no salía la Ley de Amnistía, venían constantemente la Policía de Investigaciones. Hacían chequeos por todo el barrio, cerraban desde tres cuadras para arriba y empezaban a chequear, casa por casa se metían. Papeles, papeles, y a todos los ilegales se los llevaban... Yo pienso que a nosotros no nos aceptan aquí, que no les gusta que nosotros estemos aquí, estemos en su país, que estemos echando raíces acá, porque ellos piensan que cuanto más nos asentemos en esta ciudad o en este país, más difícil va a ser irnos... En general eso es lo que pasa en Chile con los funcionarios, que no nos aceptan. Y yo les doy la razón, porque aquí hay mucha gente que se porta mal, y a todos nos involucran (H., comerciante peruano de calle Rivera).

La entrevista realizada con un inspector municipal de la comuna de Independencia (en febrero de 2009) camina en la misma dirección. Luego de una conversación iniciada con expresiones violentas y xenófobas para referirse al colectivo peruano -"los peruanos son cochinos" o "los peruanos han traído la tuberculosis a Chile"-, le consultamos por las frecuencias con que se realizan inspecciones en territorio municipal y por los criterios seguidos para la definición de recorridos. El inspector partió poniendo énfasis en la concentración de negocios peruanos en la calle Rivera y alrededores, agregando que "se controla selectivamente en la calle, al azar". Queda manifiesta la operación de estos lugares como espacios marcados por la falta, la irregularidad, la carencia. El espacio está ya denotado.

\section{La higiene o "el miedo a ser tocado"6}

Como dispositivo fijador de la diferencia que la migración produce en el espacio urbano santiaguino, la actuación de la higiene y salubridad emerge como marcador o estigmatizador de nuevas poblaciones migrantes (Gissi \& Soto, 2010). El comercio ambulante protagonizado por los migrantes en Santiago tiene especial visibilidad en la calle -especialmente la venta de comidas preparadas-, convirtiéndose en objeto de señalamiento por las autoridades locales y la población en general. Esto provocó que se discutiera públicamente la posibilidad de relocalizar los comercios en otros espacios de la ciudad (Garcés, 2010).

La higiene como separador de grupos es un fenómeno que tiene larga data. Sin embargo, debido a la novedad del tipo de inserción urbana que presenta la migración peruana en Santiago, el problema emerge con particular notoriedad, desatando un conflicto que involucra a agentes y actuaciones diversas: acciones emprendidas por los propios comerciantes peruanos, episodios represivos protagonizados por Carabineros, actuaciones funcionarias desde organismos públicos, debates en concejos municipales y sus medidas resultantes, presencia mediática, etcétera. A continuación aprovechamos una serie de eventos registrados en febrero de 2009, relacionados con el debate y conflicto resultantes de un supuesto permiso provisorio otorgado a un grupo de comerciantes peruanos por el entonces alcalde de Santiago, 
en que se autorizaba la venta de comida preparada en la primera cuadra de la calle Catedral, a unos pocos metros de la plaza de Armas ${ }^{7}$.

Decíamos que la higiene ha operado históricamente como un separador de grupos que eventualmente comparten cierto espacio. En este sentido, es imprescindible dar cuenta de la relación paradigmática establecida entre segregación espacial, minoría étnica e higiene, relación pesquisable en la literatura científica para momentos históricos y zonas geográficas diversas (Anderson, 1987; Murunga, 2005; Nightingale, 2006). Nightingale, en su estudio sobre la segregación espacial en Baltimore a comienzos del siglo xx y su comparación con procesos similares en ciudades coloniales de África y Asia, muestra cómo se termina argumentando política e ideológicamente, desde la superposición de tres conversaciones: (i) la discusión y formación de una geografía mundial de las razas; (ii) la relación entre un conocimiento de las razas y una reforma urbana donde la salud pública resulta central; y (iii), a partir de ello, la configuración de mercados de propiedad. Apunta a cómo, en el marco de discusiones en que participan funcionarios públicos, profesionales, académicos y propagandistas, se generan las condiciones para la creación de distritos residenciales separados racialmente (Nightingale, 2006, pp. 668-669), donde "la higiene" deviene fundamental.

Según Curtin (1985, p. 596), el conocimiento médico desarrollado desde el siglo XIX tiene importantes impactos sobre la segregación urbana, al reconocerse como empíricamente probado que algunas enfermedades (como la viruela) tenían el poder de extenderse de una persona a otra, mientras otras (como la malaria) aparecen como endémicas en determinadas partes del globo, aunque no sean claramente transmisibles por el contacto personal. Más allá de la casuística, señala Curtin, la planificación de la ciudad es influida por una segregación sanitaria, cuyo "nacimiento e importancia serían contemporáneos a la legislación de zonas para las ciudades norteamericanas y europeas, en las que algunos aspectos fueron también ostensiblemente justificados con fines sanitarios" (p. 613). Murunga, en su trabajo sobre la segregación en Nairobi (Kenia), señala que, entre los administradores coloniales, existe la idea de que hay algunas razas, grupos étnicos e incluso clases sociales cuyos hábitos, costumbres y modos de actuar los predisponen a condiciones de vida insalubres y faltas de higiene. En esos ámbitos, señala, se definía la limpieza como característica fundamental del ser inglés en oposición a la imagen de enfermedad y patología asociada a los grupos africanos. Los africanos son pensados como sucios, depravados y feos (Murunga, 2005, citado en Martínez Veiga, 2007, p. 20).

No queremos plantear con esto que los espacios de centralidad migrante (Garcés, 2011 b) en el centro de Santiago (u otras zonas) respondan solamente a un proceso de segregación espacial planteado en estos términos, sino que estas localizaciones pueden responder también a otros fenómenos simultáneamente. Por ejemplo, en el caso del centro de Santiago, la segregación espacial coincide con una cuestión de oportunidad, con la decadencia de una zona comercial y con su revitalización a

7 Encontramos una aproximación similar en el trabajo de Stoller (1996) acerca del funcionamiento e intento de relocalización de un mercado de inmigrantes en Nueva York, donde las diferentes comunidades, étnicas, religiosas y lingüísticas, entran en conflicto con las políticas propuestas desde del ámbito municipal. 
partir de distintas actividades económicas originadas con la migración. Así, nuestro interés apunta ahora a la articulación (o actuación) del mismo principio mediante el cual la higiene opera como marcador de diferencias entre grupos nativos y extranjeros, como ideología que mantiene la separación entre unas poblaciones y otras, como un proceso metonímico de conversión de los grupos étnicos en algo insalubre en si mismos (Martínez Veiga, 2007, p. 22). Se trata, en definitiva, de la construcción de un estereotipo (lo antihigiénico, lo insalubre) anclado al espacio, que se localiza denotando a grupos específicos, cooperando en su reproducción como hecho social.

En Santiago, el problema de la higiene y la presencia migrante está asociado fundamentalmente al comercio ambulante de comidas peruanas en calle Catedral. Esta venta ha estado presente en la zona desde los años noventa; ha aumentado en forma paralela al incremento del flujo migrante, hasta llegar en los últimos años a la preparación de comida en la calle. La marcación que establece la higiene, su función diferenciadora de poblaciones y la conversión que hace de determinados grupos en insalubres en sí mismos, aparece primero en el discurso de los usuarios autóctonos de estos espacios:

Lo que sí no sé qué piso usaría yo, porque son muy cochinos, muy cochinos. O sea, la inmundicia que dejan sábado y domingo es impresionante. Porque estas comidas que las venden en esas cosas de polietileno, las tiran ahí no más... Porque tú no estái acostumbrado a ver peleas cada dos segundos ahí, o que la gente te venda la comida en la calle. Tú estái acostumbrado a que te vendan un helado o un superocho, pero no a que te vendan comida-comida. Que te vendan los jugos y que lo saquen de un balde grande, y el tipo mete la mano pa' dentro... no estái acostumbrado (M., comerciante chileno de calle Catedral).

Las quejas de los vecinos residentes en la zona y demás comerciantes son bastante intensas, convirtiéndose a su vez en legitimadoras de acciones emprendidas por la fuerza policial, o de políticas implementadas desde el Municipio. Pero en ningún caso son exclusivamente actores chilenos los que participan de la caracterización del "espacio antihigiénico" en el centro capitalino. Los distintos mecanismos, actividades y discursos que localizan y caracterizan lo migrante en su insalubridad, no constituyen fuerzas que actúan como una denotación de lo local/autóctono respecto de lo migrante, en dirección unívoca. Se observa más bien la enunciación de discursos que, reproducidos por los migrantes, se orientan a una diferenciación y jerarquización interna de los grupos que componen la migración peruana en Santiago:

Yo estoy de acuerdo en algo, no puedo soslayar esto. Hay gente que en base a sus costumbres comete muchos errores. Por ejemplo, errores en cuanto a limpieza pública. Hay gente que vende comida porque no tiene otra forma de sostenerse, de sustentarse. Además han encontrado una veta en venderles comida a trescientas personas que están ahí todo el día, todos los días - gente que tiene que tomar desayuno, almuerzo, comer- a precios más bajos que los restaurantes chilenos y que los peruanos, porque hay restaurantes peruanos en este sector. Entonces, me parece bien que puedan vender; lo que me parece mal es que dejen las cosas sucias o que no incentiven al peruano... Por ejemplo, tú vendes acá en esta vereda que da hacia 
el norte, y en la vereda sur, que es la pared de la Catedral, la gente se va a comer... Entonces le venden en un tupper, sellado, con tenedores de plástico, y viene una bolsita plástica para que después lo envuelva y lo pueda botar. Y a veces la gente lo come y lo deja abandonado... Entonces lo que debiéramos es proponer un mayor grado de limpieza. Me parece lícito que la comunidad chilena se pueda quejar si es que hay eso. Eso pasaría también en el Perú (Pastor evangélico de la comunidad peruana en Santiago).

Las consecuencias del uso del espacio asociado al comercio ambulante se fijaron en los discursos como elemento estigmatizador, con una potencia que permea a las poblaciones autóctonas. Se han fijado también entre los migrantes, reproduciendo regionalismos y concepciones de clase traídos desde sus lugares de origen. En esta línea, Jürgen Golte, estudioso de la migración rural-urbana a la Gran Lima, da pistas precisamente de la nueva cultura urbana, aquella de la migración que se inserta/ superpone a la ciudad criolla. A pesar del contexto de estrechez de la economía, esta migración generó formas económicas propias, reproduciendo modelos de capitalismo temprano aparentemente arcaicos en la organización de la producción y en sus procedimientos técnicos, con los cuales se sitúan en la estructura económica de la ciudad, produciendo, vendiendo, comprando y dinamizando el crecimiento urbano (Golte \& Adams, 1990, p. 74; Golte, 1999). La superposición entre la Lima de los criollos y aquella de los migrantes provincianos redunda en una producción mutua de estereotipos, en que se estigmatiza a los serranos como brutos, sucios e invasores (Golte \& Adams, 1990, pp. 85-89). En el caso de la migración peruana en Santiago, estos regionalismos suponen el acento en lo cultural como desventaja que explica el desarrollo de prácticas insalubres en el espacio público.

Son provincianos... se nota tanto físicamente como en la manera de comportarse. Porque igual allá en Lima, nosotros mismos los de Lima renegamos de los provincianos. Porque a veces, cuando uno camina por Lima, ve las calles cochinas. Claro que los de Lima también lo hacen, pero ellos están ahí, piden limosna, están con varios bebitos, están dándole de mamar a uno... Mandan a los niñitos a vender... Entonces nosotros mismos en Lima renegamos de eso. Y eso pasa aquí también. Y eso a veces molesta. Si a mí, siendo peruana, en este que no es mi país me molesta, imagínate a un chileno (C., peruana, empleada de Centro de Llamados e Internet).

Más allá del problema de la higiene, las nuevas formas de hacer en público, la nueva urbanidad configurada en los usos del espacio público por los migrantes peruanos, entran en conflicto con los usos privilegiados por la institucionalidad pública, asentados en la legibilidad de la pura circulación de transeúntes y la asepsia de un centro histórico puesto allí como espacio patrimonializado. La percepción de hacer un uso inapropiado o ilegítimo del espacio del centro también hace carne entre los migrantes, impactados por los dispositivos que operan sobre el espacio urbano inseguro, delictual e insalubre.

Además, estas actividades tienen tal notoriedad en el espacio público, por ubicarse cercanamente a edificaciones de importante valor patrimonial de la ciudad, que han constituido de manera constante un tema de las campańas electorales municipales que se desarrollan cada cuatro años. En 2008 asumió como alcalde 
de Santiago Pablo Zalaquett (Unión Demócrata Independiente, UDI), quien, colocando como presentación de su esfuerzo la ascendencia peruana con que cuenta, propuso dar una "solución definitiva" al problema peruano en el centro. Durante febrero de 2009, de acuerdo con las informaciones que aparecen en prensa y lo que nos informan algunos representantes de organizaciones peruanas en Santiago, se llegó a un acuerdo consistente en la autorización provisoria al seńalado grupo de comerciantes ambulantes, para que llevaran a cabo su actividad comercial los días viernes, sábados y domingos, entre las 18 y 23 horas, hasta la fecha límite del 31 de marzo del mismo año, cuando sería prohibida toda actividad de ese tipo. El espacio que se les permite ocupar consiste en unos cincuenta metros de la primera manzana de la calle Catedral, por la vereda en que se encuentran los comercios establecidos, la que concentraba normalmente el comercio ambulante previo a la autorización, y previo a que se hiciera más estable el control de Carabineros.

La autorización resulta singularmente interesante, porque desató un campo de discusión al que se integraron actores hasta entonces relativamente ausentes. Emergió la actuación de la organización Comité de Refugiados Peruanos en Chile ${ }^{8}$, que intentó legitimar su acción y cobrar protagonismo mediante un pretendido rol mediador entre autoridades municipales y comerciantes ambulantes. Ya en febrero, en vísperas de comenzar el período autorizado de venta en la calle, publicaron un primer comunicado?:

Hoy 19 de Febrero dirigentes de nuestra agrupación, del Apers [Asociación de Peruanos Residentes en Santiago] y asesores técnicos nos reunimos con el alcalde don Pablo Zalaquett (luego de múltiples diferencias y desencuentros)... El Alcalde señaló expresamente que está por la formalización de los trabajadores ambulantes, que está dispuesto a dar autorizaciones y va a tratar los temas con las dirigencias de los mismos, declaración que saludamos y esperamos que se cumpla. Reconoció y manifestó su acuerdo con el uso de la vía pública, es decir, que los inmigrantes que se encuentren en calle Catedral no son objeto de persecución y que no es voluntad del municipio impedir que los inmigrantes se reúnan en dicho lugar... Respecto de la reunión sostenida ayer con personas mandadas por el consulado peruano, que dicen ser representantes de los comerciantes ambulantes de Catedral, dejamos en claro que no existe ninguna organización de comerciantes ambulantes peruanos de Catedral, que las nombradas sesenta personas no son necesariamente los que denominan comerciantes de cocinerías y que tenemos denuncias de cobros indebidos y otras irregularidades que se han dado para formar la antes indicada lista... (APERS, Asociación de Peruanos Residentes en Santiago; destacados en el original).

Sin discutir la legitimidad de la acción propuesta por APERS, queda clara su intención de validarse como representante de la comunidad peruana. Esta organización va a desempeñar -o intentar desempeñar- un rol en lo que se ha impuesto como solución al problema: la relocalización de actividades. El reclamo de la organización pasó, centralmente, por la consideración de la concentración en el centro de

Se trata de una organización constituida ya en abril de 1998.

9 En concreto se trata de un folio con el logo del Comité de Refugiados Peruanos en Chile, y que era entregado a quienes circulaban por calle Catedral aquellos días. 
Santiago como algo que debe enfrentarse desde una política global que incluya la no criminalización de la permanencia de las personas en el espacio público, y que en el caso de los comerciantes ambulantes, los considere y trate como uno más de los actores involucrados en estas actividades informales, desarrolladas además en distintas zonas del Gran Santiago y no precisamente por extranjeros. A fines de febrero se hizo efectiva la autorización de un número de entre cincuenta y sesenta comerciantes, instalados en el espacio antes señalado, dedicados a la preparación/ venta de productos en condiciones bastante precarias (Figura 3).

FIgura 3 | Comercio informal de comidas peruanas en calle Catedral, viernes 6 de marzo de 2009

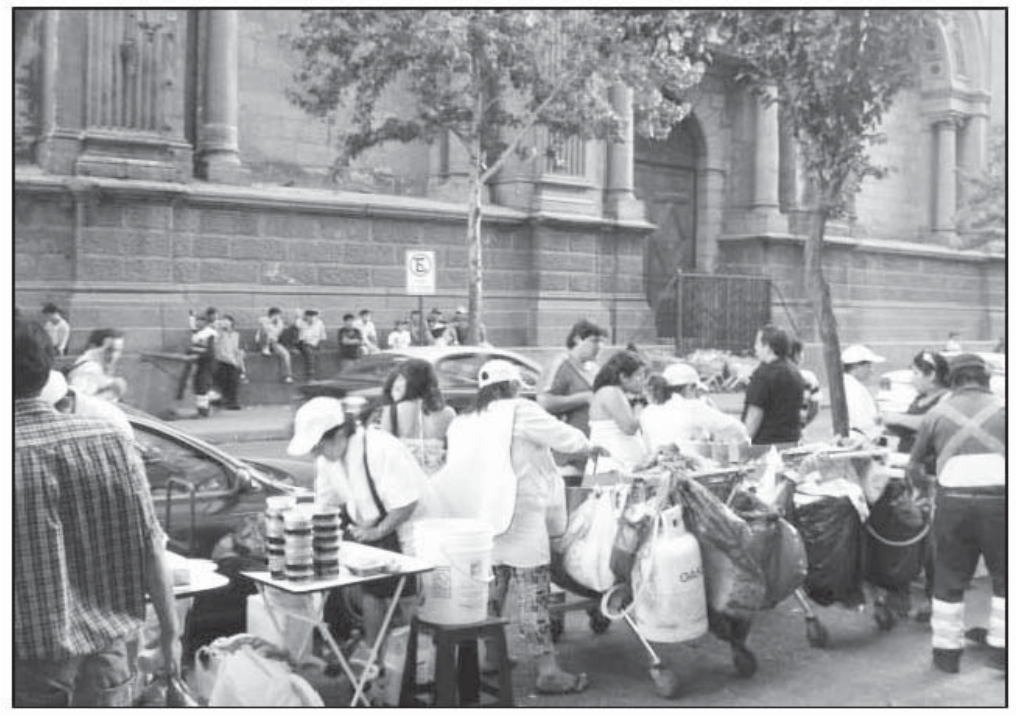

FUENTE FOTOGRAFÍA DE ALEJANDRO GARCÉS H. (2009)

A partir de ese momento, paralelamente a la aparición en prensa de la noticia sobre la autorización, tuvo lugar un debate al interior del Concejo Municipal de Santiago, órgano donde se encuentran representados los distintos partidos políticos nacionales. Este debate hizo emerger nuevamente el tema de la higiene, a veces de manera autónoma, en otras ocasiones en relación con la ilegalidad de las prácticas, pero en cualquier caso como elemento que connota una actividad, unos espacios en concreto, y de allí a los grupos que la llevan a cabo. El 27 de febrero de 2009 el concejal Pedro García, democratacristiano y exministro de Salud del gobierno de Ricardo Lagos (2000-2006), abrió los fuegos del Concejo señalando:

...quisiera que quedara constancia en Acta de la publicación del diario La Tercera del día 25 de febrero, cuyo título dice: "Cocinerías podrán establecerse en el centro hasta el 31 de marzo". Al respecto, quisiera señalar que el viernes pasado en el diario El Mercurio fue publicada una carta mía, donde planteo mi enérgico rechazo a una autorización que me parece del todo ilegal y que puede poner en dificultades los intereses de este municipio y sobre todo la Sanidad y el buen vivir de las personas en esta Comuna. Dicha carta señala: "Gran sorpresa me causa enterarme por la prensa que en 
una medida inconsulta, populista e ilegal se estaría autorizando la instalación de este comercio riesgoso sin trazabilidad ninguna, que amenaza la salud de las personas y al comercio establecido; se incentiva con esta medida la propagación de un ilícito manifiesto que compromete diversos barrios de la Comuna y que favorece otros actos delictuales de mayor gravedad. Es por esto y dada mi condición fiscalizadora, que a través de la prensa le solicito al Alcalde no trasgredir, entre otras, el Código Sanitario y diversas normas tributarias que han permitido que Chile avance, descartando prácticas medievales de consumo alimentario... (Concejo de Santiago. Sesión Ordinaria No 7/2009, celebrada en el Salón de Sesiones. Miércoles 11 de marzo, 16 horas).

En sesión posterior, un concejal de derecha retomó esta temática, haciendo un reclamo contra la Intendencia de la ciudad por la supuesta autorización dada a la reunión de inmigrantes en espacios públicos. En su reclamo, la asociación entre migración, falta de orden y limpieza se extiende ya no solo a los peruanos:

Esta autorización está firmada por el Intendente subrogante a quien intenté ubicar durante el día de ayer pero no tuve éxito. Entiendo que ellos han visto en los medios de comunicación que en este Concejo estamos intentando limpiar la ciudad, a fin de tener una Comuna capital ordenada donde se cumpla con las normas, sin embargo permiten que en la Plaza de Armas se reúna todos los días domingo de 10 a.m. a 20 hrs. un grupo indeterminado de inmigrantes peruanos o de cualquier nacionalidad que pueden ser 100 o 500, lo que creo no contribuye al orden público ni facilita las actividades que estamos criticando en este Concejo. Mañana nuevamente voy a insistir en ubicar al Sr. Intendente titular y si no me contesta, en la tarde presentaré una solicitud de permiso a la Intendencia para que la Comunidad coreana se reúna todos los días domingo en la calle donde vive el Sr. Intendente, para ver si le gusta que todos los días domingo allí haya una reunión masiva de otro grupo de inmigrantes, a lo mejor así logre conseguir que me devuelva el llamado (Concejo de Santiago. Sesión Ordinaria No 7/2009, celebrada en el Salón de Sesiones. Miércoles 11 de marzo, 16 horas).

Hemos señalado que el papel de la higiene en relación con la segregación es un fenómeno de larga data, ya pesquisado por Sennett en su descripción del gueto judío en Venecia (siglo Xv). El gueto, en tanto forma espacial de la distancia entre poblaciones, es un claro ejemplo de racismo y segregación (Sennett, 1997, pp. 232-233). No estamos afirmando que la perspectiva en Santiago sea de este tipo, pero sí queda planteada la potencia de la higiene como dispositivo en los términos señalados. El "hay que limpiar la ciudad" reproducido por los concejales de Santiago es un síntoma de aquello. El discurso del concejal citado argumenta desde la producción de un saber médico, que coloca el problema de la higiene como descriptor básico de prácticas (de producción y consumo alimentario) y, consecuentemente, del espacio. El peligro que sugiere el contacto con estos consumos supone, en su perspectiva, el cuidado y protección de la población local, ante quienes ha de responder como representante.

Pese al tinte alarmista, es sintomático también que quien enarbola este discurso higienicista sea un concejal de profesión médico. De hecho, su alocución parte haciendo referencia a su condición profesional: un intento de hacer más legítima la intervención. Según Frenkel y Western (1998), el desarrollo de la ciencia médica 
marca un antes y un después en los fenómenos de segregación residencial. En el caso que ellos estudiaron -asentamientos coloniales británicos en el África Tropical de principios del siglo $\mathrm{xx}$-, la identificación por parte de distintos investigadores de la acción del vector mosquito como propagador de la malaria determinó que la prevención tomara una nueva forma en la segregación de las viviendas de colonizadores y nativos. La segregación se reinscribe como discurso "estrictamente" científico, una suerte de "objetiva" justificación médica (ibíd., p. 226). La interpretación del fenómeno incluye también el deseo de algunos oficiales coloniales de salir del asentamiento africano, para disfrutar de la ausencia, en la noche, de los ruidos y olores de la ciudad nativa, pero no al grado tal de no contar con sirvientes africanos en sus casas. De cualquier modo, contra la supuesta objetividad y cientificidad de estos saberes, el estudio de Frenkel y Western revela el hecho de que el lenguaje médico ha servido como recurso de significado más social que científico, porque, por ejemplo, en el caso de Sierra Leona la salud de los oficiales era similar en los distintos espacios segregados (ibíd., p. 227).

Para el caso de Santiago, resulta dudosa la objetividad o cientificidad de afirmaciones amparadas o legitimadas en saberes médicos. Ellas entran en contradicción con, por una parte, cualquier rápida observación de la profusa red de preparación y venta ambulante de comidas a lo largo del Gran Santiago (donde las masas de comerciantes y consumidores consisten fundamentalmente de población local chilena); y por otra, con la alta valoración de la gastronomía peruana entre los sectores medios y altos, que son capaces de integrar estas novedades a sus dietas (en restaurantes peruanos de alto standing o de la contratación directa de servicio doméstico peruano), al mismo tiempo que rechazan la práctica popular que de ella se hace en la calle. Los discursos que desde distintas agencias abundan en el peligro sanitario o bacteriológico del comercio ambulante, cooperan en la producción de estereotipos que aplican al colectivo y a sus espacios.

La producción de estos espacios como inseguros, criminales y/o antihigiénicos, se da en zonas específicas de la ciudad. En el caso del municipio de Santiago, la venta (y también la preparación) ambulante de comidas peruanas se da en un espacio que goza de una particular singularidad o visibilidad pública, al ubicarse a un costado de la Catedral, colindando con la plaza de Armas. La transgresión que implican los usos de una zona comprendida como el centro histórico de la ciudad, resulta un elemento clave que quizá permita explicar la importancia que se da al intento de terminar con esta actividad en el Concejo.

Si la ubicación de migrantes peruanos en espacios urbanos es colindante con edificaciones de valor patrimonial del centro de Santiago, es cierto también que esta ocupación se desarrolla en calles o cuadras donde verificamos un notorio decaimiento del tejido comercial autóctono chileno, y donde el emprendimiento migrante ha generado una sustitución comercial (Garcés, 2011b). Así, no podría señalarse una competencia con los comercios y servicios que la renovación urbana en el centro (con la ampliación del Metro, reforma de la plaza de Armas y peatonalización de calles) privilegió. Los usos migrantes se desenvuelven en los márgenes de esta transformación, casi como que si la misma no les tocara. 
La transgresión en los usos del espacio que describe el comercio ambulante y su tematización como desestructurador de un orden, trata también de procesos transversales al colectivo peruano, ya sea comerciantes (ambulantes o no) o miembros de organizaciones. Un comerciante ambulante peruano en la calle Rivera plantea cómo, estratégicamente, y luego de intentar desarrollar este tipo de comercio en zonas más céntricas, la tolerancia policial en la calle Rivera ha constituido factor central para la ubicación de su actividad:

...sí distingue porque allá es mal visto. ¿Por qué? Porque es céntrico, ¡uy! hay muchos turistas que llegan de diferentes países el mundo. Yo estoy de acuerdo de que puedan tener un puesto donde vender que sea más higiénico, como se dice. Yo, por esa parte que son mis compatriotas, a veces no estoy de acuerdo tampoco. No tienen adecuadas su herramientas pa' trabajar... A veces hay perros, hay basura, todo lo que comen lo tiran al suelo. Deben tener algo, un tacho... le doy toda la razón al Municipio porque a veces se ve todo feo, feo... Aquí estamos retirados, nos vemos entre nosotros no más, ¿¿ves? Aquí estamos como escondidos, aquí todos los peruanos que vivimos acá ya sabemos las costumbres... para hacer deporte, comer, refrescarse, distraerse... Acá no molestan los carabineros; yo creo que acá se dan cuenta que acá no está en el centro. Acá no vienen los turistas... (H., comerciante peruano calle Rivera, comuna de Independencia).

En este escenario se lleva adelante una negociación con la asociación de comerciantes ambulantes antes señalada, más la mediación de agentes del consulado peruano. Lo interesante, a nuestros efectos, son los términos en que ella se realiza; la concordancia en cuanto a que la solución frente al problema sería la relocalización/ reubicación del comercio ambulante peruano. La "imagen” de la ciudad, la limpieza de su centro histórico, con independencia de la situación particular de los migrantes y de las causas del fenómeno, se convierte para los concejales de Santiago en el principal argumento para pensar en una reubicación de este comercio y la mediación para este fin del Municipio. Paralelamente, se presenta la posibilidad de rentabilizar la actividad por medio de la exotización de sus prácticas culinarias. En las sesiones del Concejo, algunos representantes de la derecha afirman esta línea de acción:

En la reunión se conversó con los dirigentes de la comunidad peruana donde le hice ver al Sr. Alcalde y a los dirigentes que siempre me opondría a cualquier tipo de comercio en la vía pública, ya que los espacios públicos son determinantes para que una ciudad funcione y cómo la ve la gente, por esa razón surgió la idea de formar una Mesa Técnica y buscar un inmueble para arrendar, tal vez dividiendo los costos entre el Municipio y los comerciantes, para que pudieran ejercer el comercio y la venta de comidas. (...) Otra de las cosas de que se habló en esa reunión es que ellos estaban dispuestos a darles cabida a otros inmigrantes, ya que hay personas de otras nacionalidades que también están vendiendo productos en la calle en forma esporádica, motivo por el cual están dispuestos a compartir con ellos lo que podría ser un lugar típico de comidas extranjeras, que significaría para este Municipio contar con un lugar agradable, ponerles término a las cocinerías ilegales y descartarnos, porque tanto el Alcalde como los Concejales nos comprometimos 
con nuestros vecinos a limpiar la Comuna, a subirla de categoría y eso significa poder sacar todas las cocinerías y esta venta de alimentos que es absolutamente perjudicial para nuestros vecinos y para los transeúntes de la Comuna (Concejo de Santiago. Sesión Ordinaria No 6/2009, celebrada en el Salón de Sesiones. Viernes 27 de febrero, 16 horas).

De este modo, la autoridad municipal propone una actuación facilitadora, en la perspectiva de encontrar nueva ubicación para la actividad en las condiciones de legalidad y sanidad requeridas. Se proponen dos lugares ubicados dentro del territorio municipal, pero alejados del centro (en la zona de Franklin una alternativa, en la del Parque de los Reyes la otra). El Municipio operaría como aval del alquiler del espacio y de la inversión necesaria para el establecimiento de sesenta puestos comerciales - de los cuales cuarenta corresponderían a cocinerías y veinte a puestos de servicios (Internet, telefonías, giros de dineros, productos peruanos)-. El mismo Municipio facilitaría la obtención de las patentes y permisos sanitarios necesarios, en coordinación con las autoridades sanitarias correspondientes. A partir de allí, se ha producido una suerte de división al interior de la asociación de comerciantes ambulantes, entre aquellos que se han "alineado" con la propuesta municipal y aquellos que, aun manteniendo el acuerdo respecto de la necesidad de reubicación de la actividad, critican el alto costo que esto supondría a los comerciantes. Organizaciones como el Comité de Refugiados Peruanos en Chile, que desde un principio intentan establecerse como mediadores del conflicto, parecen comenzar a perder incidencia en la discusión, al reducirse esta al específico problema de los comerciantes ambulantes, dejando de lado lo que en la perspectiva de estas organizaciones sería una solución integral al problema de los migrantes peruanos en Santiago. Ellos insisten en una demanda por "el espacio" de lo peruano, lo que podría pasar por la peatonalización de las calles donde se desarrollan estas actividades, o por la construcción de un edificio que reúna estas actividades en el centro capitalino ${ }^{10}$. La perspectiva de esta organización resulta paradójica a los efectos de lo que estamos presentando. Se plantea la creación de un nuevo espacio, o una suerte de recuperación del espacio ocupado en el centro, pensado a partir de la peatonalización de la calle, que la coloca en sintonía con la idea de hacer productivo el espacio en términos turísticos, posición ya manifestada por la autoridad municipal. Este conjunto de intenciones choca con la evidencia de que la presencia peruana no solo no es bienvenida en el centro, sino que es hostigada por las distintas agencias institucionales. La paradoja se encuentra en que el interés en recuperar de esta forma el espacio ocupado por los migrantes supone la visibilidad pública de esta presencia, que se contradice con la elaboración de los proyectos que, junto con la reubicación de los comerciantes ambulantes propuesta por el Municipio, tienden precisamente a "invisibilizarlos” en el espacio público.

10 Esta organización cuenta con un proyecto elaborado por un tesista de maestría de la Universidad Central de Chile, trabajo que diseña la construcción de un edificio que contaría con patios de comidas, oficinas de atención al migrante, cursos de capacitación, auditorios, etcétera. 


\section{Conclusión}

Las distintas formas en que emerge el comercio ambulante peruano en Santiago, sus distintos emplazamientos en espacios entendidos como patrimoniales y en otros que no lo son, las formas de nombrar la diferencia que esta extranjeridad introduce en la ciudad, nos muestran los también diversos modos en que los dispositivos de criminalización e higienización del espacio se reproducen y actualizan en la coacción sobre las prácticas de apropiación del espacio desarrolladas en Santiago. Ya se trate de actividades económicas, de reunión o pura socialización sin más, hemos descrito el modo cómo estos dispositivos inauguran denotaciones y estigmas que operan circunscribiendo esta diferencia nacional a unos espacios concretos, separándolos del resto, marcándolos, en términos tanto efectivos o como proyecto.

La concentración espontánea de lo migrante peruano, o su carácter programático a causa de la actuación de estos dispositivos, acusa una proyección espacial de la diferencia entre las poblaciones, una naturalización de esa diferencia (Bourdieu, 1999, p. 120) y de la histórica relación entre segregación espacial, minoría étnica e higiene. Más allá de la oposición antes presentada entre representaciones del espacio y espacios de representación como formaciones dicotómicas, nos encontramos ahora con sujetos migrantes que las integran y se apropian de los discursos que marcan esta necesaria separación espacial, o -si se quiere- con la reificación de espacios contenedores para ella.

\section{Agradecimientos}

A Menara Guizardi, por la lectura y comentarios a este manuscrito.

\section{Referencias bibliográficas}

Anderson, K. (1987). The idea of Chinatown: The power of place and institutional practice in the making of a racial category. Annals of the Association of American Geographers, 77(4), 580-598. doi: 10.1111/j.1467-8306.1987.tb00182.x

Arriagada, C. \& Granifo, H. (2008). Monitoreo de medios sobre noticias referidas a migrantes internacionales. El caso de Santiago de Chile. Santiago de Chile. miurbal (Observatorio experimental sobre las migraciones internacionales en las áreas urbanas de América Latina). http://www.miurbal.net/documents/Santiago05_DIC07.pdf

Bourdieu, P. (1999). Efectos de lugar. En P. Bourdieu (Ed.), La miseria del mundo (pp. 119-124). Madrid: Akal. En http://espai214.org/emiliomartinez/Efectos\%20de\%20lugar.pdf

Corsín-Jiménez, A. (2003). On space as a capacity. Journal of Royal Anthropological Institute, 9, 137-153. En http://digital.csic.es/bitstream/10261/85028/1/On\%20space $\% 20$ as $\% 20 \mathrm{a} \% 20$ capacity.pdf

Corsín-Jiménez, A. (2005). Changing scales and the scales of change: Ethnography and Political Economy in Antofagasta, Chile. Critique of Anthropology, 25(2), 2005, 155-174. http://dx.doi.org/10.1177/0308275X05052019 
Curtin, P. (1985). Medical knowledge and urban planning in Tropical Africa. American Historical Review, 90(3), 594-613.

Delgado, M. (1999). El animal público. Hacia una antropología de los espacios urbanos. Barcelona: Anagrama.

Delgado, M. (2007). Sociedades movedizas. Pasos hacia una antropología de las calles. Barcelona: Anagrama.

Ducci, M. \& Rojas, L. (2010). La pequeña Lima: nueva cara y vitalidad para el centro de Santiago de Chile. EURE, 36(108): 95-121. http://dx.doi.org/10.4067/S025071612010000200005

Foucault, M. (2002). Vigilar y castigar: nacimiento de la prisión. Buenos Aires: Siglo XxI.

Frenkel, S. \& Western, J. (1988). Pretext or prophylaxis? Racial segregation and malarial mosquitos in a British Tropical Colony: Sierra Leone. Annals of the Association of American Geographers 78(2), 211-228. doi: 10.1111/j.1467-8306.1988.tb00203.x

Garcés (2010). Movimientos y localizaciones: espacios públicos y economias de la migración peruana en Santiago de Chile. Tesis de doctorado. Universidad Autónoma de Madrid, España.

Garcés, A. (2011a). Comercio inmigrante y economías étnicas: síntesis y críticas de los debates vigentes. Polis, Revista Académica Universidad Bolivariana, 10(29), 97-121. En http:// www.scielo.cl/pdf/polis/v10n29/art05.pdf

Garcés, A. (2011b). De enclave a centralidad. Espacio urbano, comercio y migración peruana en Santiago de Chile. Gazeta de Antropología, 27(2), 1-24. En http://digibug.ugr.es/ html/10481/18981/G27_38Alejandro_Garces.html

Garcés, A. (2012). Localizaciones para una espacialidad: territorios de la migración peruana en Santiago de Chile. Chungará - Revista de Antropología Chilena, 44(1), 163-175. En http://chungara.cl/Vols/2012/44-1/Localizaciones_para_una_especialidad.pdf

Gissi, N. \& Soto, P. (2010). De la estigmatización al orgullo barrial: apropiación del espacio e integración social de la población mixteca en una colonia de Ciudad de México. Revista INVI, 68(25), 99-118. En http://www.redalyc.org/articulo.oa?id=25816623005

Goffman, E. (1979). Relaciones en público. Microestudios del orden público. Madrid: Alianza Editorial.

Golte, J. (1999). Redes étnicas y globalización. Revista de Sociología, 11(12). En http://sisbib. unmsm.edu.pe/BibVirtual/Publicaciones/sociologia/1999_n12/art041.htm

Golte, J. \& Adams, N. (1990). Los Caballos de Troya de los invasores. Estrategias campesinas en la conquista de la Gran Lima. Lima: Instituto de Estudios Peruanos.

Lawrence-Zúniga, D. \& Low, S. (1990). The built environment and spatial form. Annual Review of Anthropology 19, 453-505. doi 10.1146/annurev.an.19.100190.002321

Lefebvre, H. (1973). El derecho a la ciudad. Barcelona: Península.

Lefebvre, H. (1976). Espacio y política. El derecho a la ciudad II. Barcelona: Península.

Lefebvre, H. (1991). The production of space. Oxford: Blackwell.

Martínez Veiga, U. (2007). Inseguridad habitacional, segregación espacial e higiene. Actas $V$ Congreso de la Inmigración en España. Valencia. Publicado en J. García Roca \& J. Lacomba Vázquez (Coords.), La inmigración en la sociedad española: una radiografía multidisciplinar (pp. 363-375). Barcelona: Bellaterra, 2008.

Mitchell, D. (2003). The right to the city. Social justice and the fight for public space. Nueva York: Guilford Press. 
Murunga, G. (2005). "Inherently Unhygienic Races": Plague and the origins of settler dominance in Nairobi, 1899-1907. En S. J. Salm \& T. Falola (Eds.), African urban spaces in historical perspective (pp. 98-130). Rochester, NY: University of Rochester Press.

Nightingale, C. (2006). The transnational contexts of early twentieth-century American urban segregation. Journal of Social History, 39(3), 667-702. doi:10.1353/jsh.2006.0008

Oslender, U. (2002). Espacio, lugar y movimientos sociales: hacia una "espacialidad de resistencia”. Scripta Nova. Revista Electrónica de Geografía y Ciencias Sociales, 6(115). http://www.ub.es/geocrit/sn/sn-115.htm

Schiappacasse, P. (2008). Segregación residencial y nichos étnicos de los inmigrantes internacionales en el Área Metropolitana de Santiago. Revista de Geografía Norte Grande, 39, 21-38. http://dx.doi.org/10.4067/S0718-34022008000100003

Sennett, R. (1997). Carne y piedra. El cuerpo y la ciudad en la civilización occidental. Madrid: Alianza Editorial.

Stoller, P. (1996). Spaces, places, and fields. The politics of West African trading in New York City's informal economy. American Anthropologist, 98(4), 766-788. doi: 10.1525/ aa.1996.98.4.02a00080

Torres Pérez, F. (2008). Los nuevos vecinos en la plaza. Inmigrantes, espacios y sociabilidad pública. AIBR, Revista de Antropología Iberoamericana, 3(3), 336-397. En http://www. redalyc.org/articulo.oa?id=62330303 